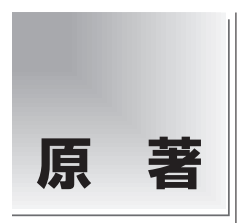

論文受付

2017 年 1 月 23 日

論文受理

2018 年 5 月 11 日

Code No. 251

\section{逐次近似応用再構成を用いた低コントラスト検出能の 評価を目的とした新しい digital phantom 作成ツールの開発}

\author{
原田耕平 大橋芳也 千葉彩佳 沼澤香夏子 \\ 今井達也 早坂 駿 片桐好美
}

札幌医科大学附属病院放射線部

\section{緒 言}

現在, multi detector-row computed tomography (MDCT) を用いた肝臓 3 phase dynamic study は, 肝 悪性腫瘍の存在㧍よび鑑別診断を行ううえで最も利用 されている撮影法である ${ }^{1 \sim 4)}$.この領域では 15 Hounsfield unit (HU) 以上のわずかな CT 值差の病変をどれ だけ認識できるかが重要であるが ${ }^{5 \sim 9)}$ ，その基準や標 準化を示す根拠は未だ発表されていない。この根拠を 示すためには臨床画像を用いて低コントラスト検出能 の評価を行うことが望まれるが，肝細胞がんに代表さ
れる腫瘤性病変のコントラストは，その大きさ，分化 度の違いや，撮影時のタイミング，使用造影剂量に よって変化するため，全く同一の濃度，大きさを有す る腫瘤のみの画像を取得するのは不可能である.

また，逐次近似応用再構成 ${ }^{10 \sim 13)}$ は画像ノイズを抑制 できるため, 既に広く臨床応用されており, 頭部領域

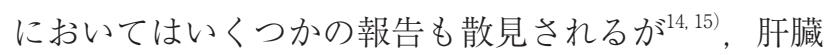
領域においては明確な根拠を示した報告はない。これ は前述したと㧍り, 肝臟領域の低コントラスト検出能 評価が複雑であることにほかならない.

\title{
Development of New Digital Phantom Creation Tool for Evaluation of Low-contrast Detectability Using Iterative Reconstruction
}

Kohei Harada, ${ }^{*}$ Yoshiya Ohashi, Ayaka Chiba, Kanako Numasawa, Tatsuya Imai, Shun Hayasaka, and Yoshimi Katagiri

Division of Radiology and Nuclear Medicine, Sapporo Medical University Hospital

Received January 23, 2017; Revision accepted May 11, 2018

Code No. 251

\section{Summary}

Purpose: We developed a novel digital phantom-creation tool that will help formulate the standard shooting method for a three-phase dynamic liver study. Here, we present data demonstrating the usefulness of this tool in the assessment of low-contrast detectability and visibility. Methods: We performed a visual evaluation by adding a spherical digital phantom with a diameter of $8 \mathrm{~mm}$ and a computed tomography (CT) value difference of 10 Hounsfield unit (HU) to images taken using filtered back projection and seven types of adaptive iterative dose reduction 3D (Weak, Mild, eMild, Standard, eStandard, Strong, and eStrong). We also examined the partial-volume effect by drawing a profile curve using a digital phantom with a CT value difference of $30 \mathrm{HU}$ and a diameter of 5 $\mathrm{mm}$. Furthermore, a digital phantom with two kinds of filters (smoothing and Gaussian) was added to the image of the home-made simulated tumor phantom to visual valuate its visibility in the phantom's low-contrast module and the digital phantom. Results: Detection sensitivity was significantly decreased in Standard, eStandard, Strong, and eStrong, and the area under the curve also decreased in a similar fashion. We confirmed that the partial-volume effect was due to the different maximum CT values in the profile curve at 4 and $5 \mathrm{~mm}$ thickness. The visibility of the low-contrast module and digital phantom was most consistent when using the Gaussian filter. Conclusion: This tool can be used for low-contrast detection ability evaluation.

Key words: low-contrast detectability, digital phantom, iterative reconstruction, liver, virtual tumors

*Proceeding author 
Digital phantom 作成ツールは CT 画像に任意の CT 值, 大きさの模擬腫瘤を加算することで, 同一の濃度, 大きさの模擬腫瘤に扔ける低コントラスト検出能の評 価を可能とする ${ }^{16)}$. しかし, 従来の digital phantom 作 成ツールは 1 断面のみの模擬腫瘤加算であるため Z 軸方向の情報を反映することは不可能であった. 10 $\mathrm{mm}$ の模擬腫瘤が $5 \mathrm{~mm}$ 厚の画像において, 2 断面も しくは 3 断面に描出されないのは不自然であり, 従来 の作成ツールでは実際の大きさや濃度差を忠実に再現 しているとはいえない。したがって, 肝蔵における腫 瘤性病変検索の画質評価を行ううえでは, パーシャル ボリューム効果を考慮した評価が必要不可欠となる。 また，加算した digital phantom は辺縁のみえ方が不 自然になる可能性があるため, 実際に撮影し再構成さ れた低コントラストモジュール等の画像と比較する必 要がある. 本研究においてわれわれは, これらの問題 点を改善すべく Z 軸方向にも対応した新しい digital phantom 作成ツールを開発し, 逐次近似応用再構成を 用いた低コントラスト検出能および digital phantom の視認性を評価し, 肝臟の撮影基準を策定するための 画質評価に利用可能か検討した。

\section{1. 方 法}

\section{1-1 新しい digital phantom 作成ツールの特徵と評価} 方法

Digital phantom は任意の断面に目標の大きさ，CT 值差のモジュールを画像に加算することにより作成さ れる (Fig. 1)。本研究にて開発した作成ツールはスラ イス厚に関係なく 1000 枚まで読み込むことが可能で あり, digital phantom を加算する中心スライス, 座標 位置, 設定 CT 值差, 半径の pixel size を任意に選択す ることができる. 更に画像保存時にスライス枚数を自 由に加算平均処理することもできる仕様にした，この 仕様により，さまざまなスライス厚の画像を，任意の スライス位置から digital imaging and communication in medicine(DICOM) 形式にて書き出すことができる ため, パーシャルボリューム効果が考慮され，より自 然な模擬腫瘤を加算可能とした。ソフト開発には Visual Studio 2015 (Microsoft)を用いC\#を使って作 成した ${ }^{17}$.

この digital phantom を評価するうえで重要なポイ ントは, 近年使用されている逐次近似応用再構成法を 使用した画像においても低コントラスト検出能評価が 可能であるか, パーシャルボリューム効果が反映でき ているか，実際撮影した低コントラストモジュールに 比べ濃度やファントム周辺の形状に打いて視認性に違

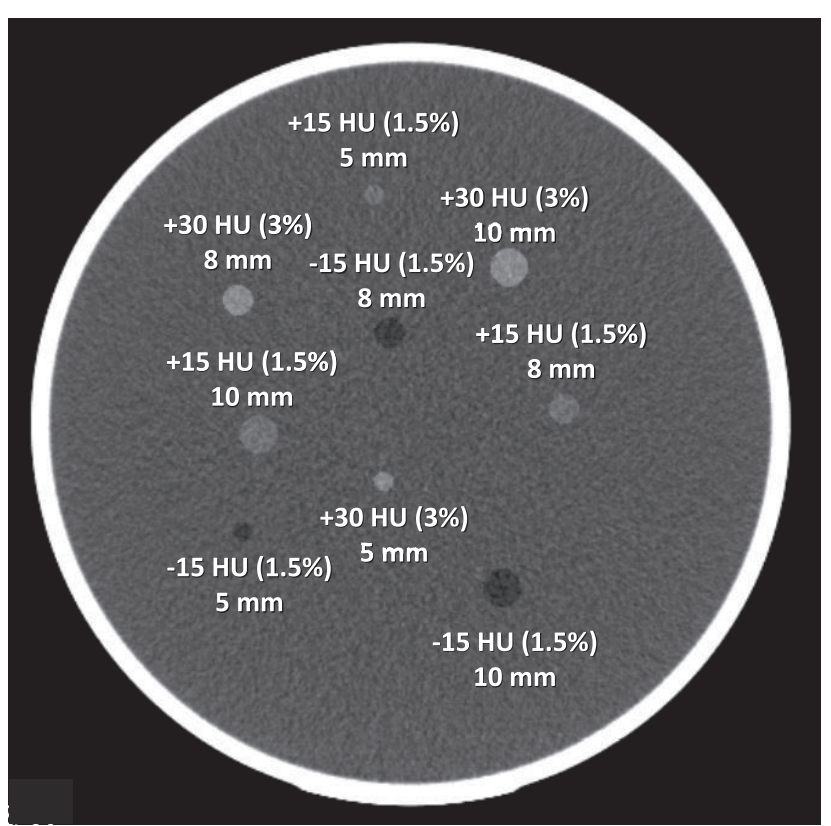

Fig. 1 Sample image created using digital phantom creation tool $(\Delta \mathrm{HU}=-15,+15$, and $+30 \mathrm{HU}$, diameter $=5,8,10 \mathrm{~mm})$.

いはないかの 3 点である.

\section{1-2 使用装置・撮影条件}

CT 装置は Aquilion Prime Ver.7(キヤノンメディカ ルシステムズ), workstation は Ziostation 2(Ziosoft) を使用した，本研究にて開発した新しい digital phantom 作成ツールが低コントラスト検出能の評価に使用 可能かを検証するためには, 基礎デー夕による挙動を 確認する必要がある。したがって本研究では水ファン トムを用いた評価に加え, 実際に低コントラストモ ジュールを封入した自作模擬腫瘤ファントムを撮影 し, digital phantom と比較する方法を選択した。

1-2-1 水ファントム

水ファントムには直径 $20 \mathrm{~cm}$ の円柱型を用い 3 回 ずつ撮影した。撮影条件は管電圧 $120 \mathrm{kVp}$, 管電流は auto exposure control (AEC; Volume EC) と 逐次近似 応用再構成 adaptive iterative dose reduction 3D (AIDR 3D)の組み合わせを filtered back projection (FBP) を含む他 7 種類 (Weak, Mild, eMild, Standard, eStandard, Strong, eStrong), 計 8 種類用 い, $5 \mathrm{~mm}$ スライス厚再構成時の standard deviation (SD)が $10 \mathrm{HU}$ となるように適宜調整した. 8 種類の 管電流は FBP が 180 mA (volume computed tomography dose index; CTDIvol $10.1 \mathrm{mGy}$ ), Weak が 150 mA (CTDIvol $8.4 \mathrm{mGy}$ ), Mild が $120 \mathrm{~mA}$ (CTDIvol $6.7 \mathrm{mGy}$ ), eMild が $130 \mathrm{~mA}$ (CTDIvol $7.3 \mathrm{mGy}$ ), Standard が 80 mA (CTDIvol 4.5 mGy), eStandard が 


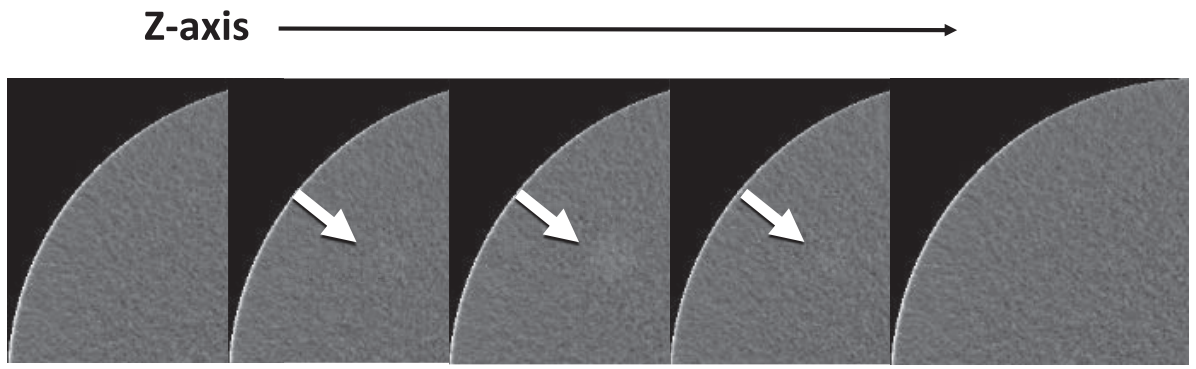

Fig. 2 Sample image created using digital phantom creation tool (arrows: $\Phi 8 \mathrm{~mm}, \Delta H U=-10$ HU).

$90 \mathrm{~mA}$ (CTDIvol $5.1 \mathrm{mGy}$ ), Strong が $50 \mathrm{~mA}$ (CTDIvol $2.8 \mathrm{mGy}$ ), eStrong が $60 \mathrm{~mA}$ (CTDIvol 3.4 mGy)であった. AIDR 3D は Weak, Mild, Standard, Strong の 4 段階の強度を有し, 更に低周波ノイズの上 昇を抑制し，低コントラスト検出能の低下を抑えたと される eMild, eStandard, eStrongの 3 種類が追加さ れた。 X 線管回転速度は $0.5 \mathrm{~s} /$ rotation，撮影スライス 厚 $0.5 \mathrm{~mm} \times 64$, ビームピッチ $0.828: 1$, スキャン field of view (FOV)は Large にて撮影した。再構成 FOV は $25 \mathrm{~cm}$, 再構成スライス厚 $0.5 / 0.5 \mathrm{~mm}$ pitch, 再構成 関数は FC14 を使用し, 50 枚ずつ再構成を行った。

Z 軸方向の評価用画像として同様に水ファントムを 撮影した。撮影条件はノイズの影響を極力抑えるた め, 管電圧 $120 \mathrm{kVp}$, 管電流は $500 \mathrm{~mA}, \mathrm{X}$ 線管回転速 度 $1.5 \mathrm{~s}$ /rotation, 撮影スライス厚 $0.5 \mathrm{~mm} \times 64$, ビーム ピッチ 0.828 : 1, スキャン FOV は Large とした。 再 構成 FOV は $25 \mathrm{~cm}$, 再構成スライス厚 $0.5 / 0.5 \mathrm{~mm}$ pitch, 再構成関数は FC14 を使用し, AIDR 3D は使用 せず $50 \mathrm{~mm}$ の撮影範囲に対し 100 枚の再構成を 行った。

\section{1-2-2 自作模擬腫瘤ファントム}

自作模擬腫瘤ファントムは直径 $240 \mathrm{~mm}$ のアクリ ル円柱容器に $110 \mathrm{HU}$ に調整した希釈造影剂を入れ, 内部に直径 $10 \mathrm{~mm}, 140 \mathrm{HU}$ のアクリル球を封入し, CT 值差を $30 \mathrm{HU}$ とした。撮影条件は管電圧 120 $\mathrm{kVp}$, 管電流は現在臨床で使用している条件に合わせ て $5 \mathrm{~mm}$ 再構成時の SD が $10 \mathrm{HU}$ (AIDR 3D; Weak) となるように調整した．X 線管回転速度は $0.5 \mathrm{~s} /$ rotation, 撮影スライス厚 $0.5 \mathrm{~mm} \times 64$, ビームピッチ 0.828 : 1, スキャン FOV は Large として 3 回撮影し た。再構成 FOVは $25 \mathrm{~cm}$, 再構成スライス厚 $0.5 / 0.5$ $\mathrm{mm}$ pitch，再構成関数は FC14 を使用した。

\section{1-3 Noise power spectrum による解析}

低コントラスト検出能の評価を行ううえで, noise power spectrum(NPS) を比較することは重要である. 特に低周波ノイズは低コントラスト検出能に影響を与 える因子であるため, 撮影した水ファントム画像の基 礎デー夕を解析する必要がある。したがって，各撮影 条件の画像におけるNPS を求め比較した。 1-2-1 で撮 影した AIDR 3D を含めた 8 種類の raw data 用い て, 画像スライス厚 $5 \mathrm{~mm}$ (10 slice), 再構成 FOV 20 $\mathrm{cm}$, 再構成関数：FC14 にて再構成を行った。測定方 法は仮想スリット法を用い, 設定 region of interest (ROI) は同一面内にて 30×256 pixel を 8 箇所とし, 10 slice かつ撮影回数は 3 回なので, 1 種類の撮影方法に 対して 30 枚の画像を用いて計測し, 平均值をとるこ とにより解析したＮNS の解析にはオリジナルソフ トを用いた。ソフト開発には Visual Studio 2015 を用 いC\#を使って作成した。

\section{1-4 サンプル画像の作成}

再構成した $0.5 \mathrm{~mm}$ 厚 50 枚の画像に対して直径 8 $\mathrm{mm}, \mathrm{CT}$ 值差 $10 \mathrm{HU}$ の digital phantom を無作為の場 所に一つ加算し, $5 \mathrm{~mm}$ 厚に変換して 5 枚書き出し 1 シリーズとした(Fig. 2)。肝臟領域における臨床画像 では $10 \mathrm{HU}$ の CT 值差を検出することは困難である $か^{16)}$, 水ファントムは均一な画像であるため臨床画像 に比べ検出が容易な環境である。したがって，本研究 では臨床画像の評価に用いる設定よりも厳しい条件に した。また，肝細胞がんの早期濃染をモデルとしたた め, 模擬腫瘤を周囲より高吸収なモジュールとした。 FBP, Weak, Mild, eMild, Standard, eStandard, Strong, eStrong に対して digital phantom を加算した 信号ありの画像を 10 シリーズずつ作成, digital phantom を加算しない信号なしの画像も同様に 10 シリー ズずつ作成し，合計 160 シリーズの画像を無作為に並 ベ替えサンプル画像とした(Fig. 3). 


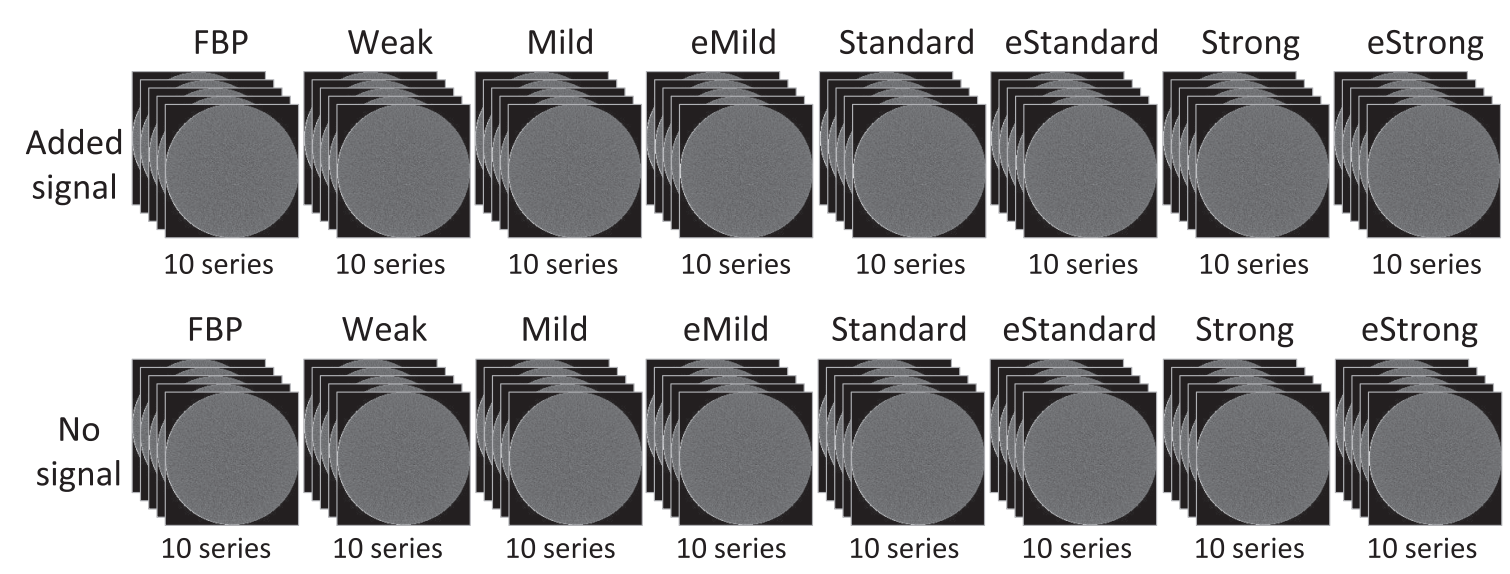

Total 160 series

Fig. 3 Added signal sample images and the no signal images in FBP and seven types of AIDR 3D (each 10 series).

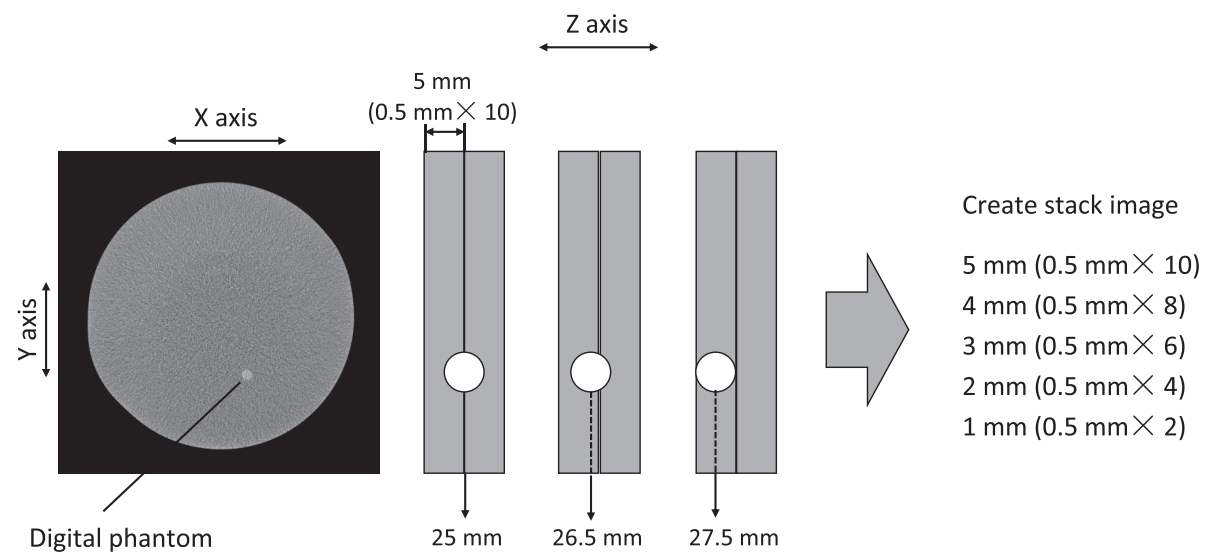

Fig. 4 Addition process of digital phantom for partial volume effect.

As a result of shifting the center position of adding digital phantom, the ratio of partial volume effect changes when images are bundled.

\section{1-5 Z 軸方向の評価用画像の作成}

1-2-1にて撮影した raw data から再構成した画像に 対して CT 值差 $30 \mathrm{HU}$, 直径 $5 \mathrm{~mm}$ の digital phantom をアイソセンタから $2 \mathrm{~cm}$ ずらし, Z 軸に対して は digital phantom の中心を 50 枚目 (スライス位置 $=25$ $\mathrm{mm}$ ), 53 枚目 (スライス位置 $=26.5 \mathrm{~mm}$ ), 55 枚目 (ス ライス位置=27.5 mm) に設定して加算した (Fig. 4). 画像スライス厚を $1 \mathrm{~mm}$ (2 枚), $2 \mathrm{~mm}$ (4 枚), $3 \mathrm{~mm}$ (6 枚), $4 \mathrm{~mm}$ (8 枚), $5 \mathrm{~mm}$ (10 枚) と, 書き出す画像も 5 種類ずつとした。

\section{1-6 評価方法}

1-4にて作成したサンプル画像を用いて放射線技師 8 名 (経験年数 2-20 年)による視覚評価を行った。観 察はすべて同一のモニ夕を用い，モニ夕から $50 \mathrm{~cm} の$ 距離にて評価を行った。ウィンドウ幅は $200 \mathrm{HU}$,
ウィンドウレベルは $50 \mathrm{HU}$ に固定した. 観察者には 本研究にて使用した模擬腫瘤の大きさと濃度差のサン プルを提示し，信号ありの場合はシェーマを書き，場 所を示してもらった.1シリーズあたりの観察時間は 20-30 秒程度とし，すべての評価を 60-90 分程度で観 察することとした。

評価方法は連続確信度法を用い, 得られた評価結果 から感度, 特異度を算出し, FBP の評価結果と各 AIDR 3D 画像の評価結果を比較した.また, receiver operating characteristic (ROC) 解析を用いて area under the curve (AUC) を求めた. AUC も同様に FBP の評 価結果と各 AIDR 3D 画像の評価結果を比較した。

1-5にて作成した画像に対して, digital phantom 加 算座標に円形の ROI を設定し, 同座標の $Z$ 軸方向に おける CT 值を測定した. 得られたグラフを比較し,パー シャルボリューム効果が反映されているか確認した。 


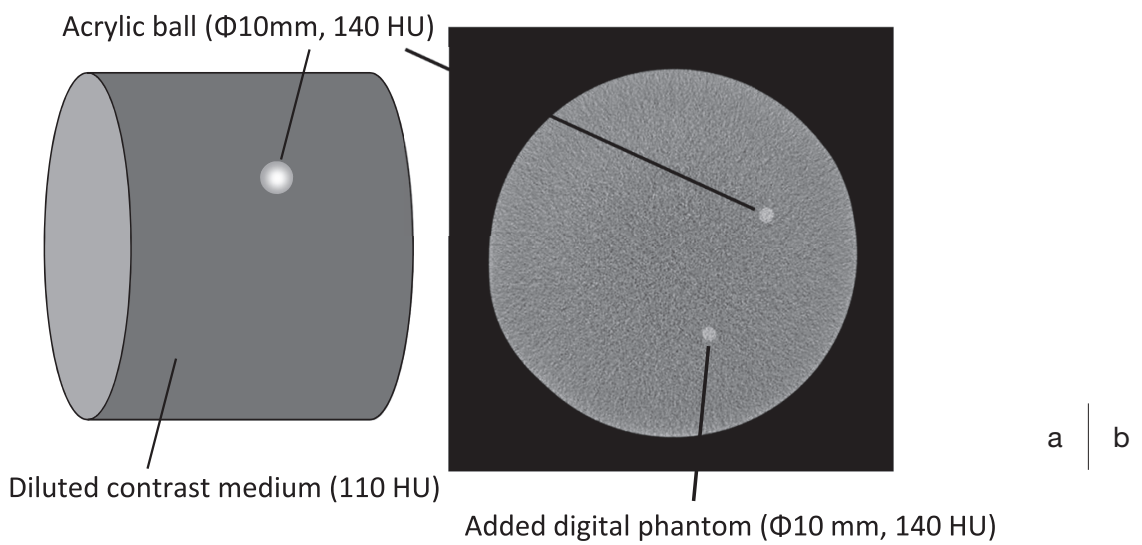

Fig. 5 Home-made simulated tumor phantom (a), reconstructed image with digital phantom added (b).

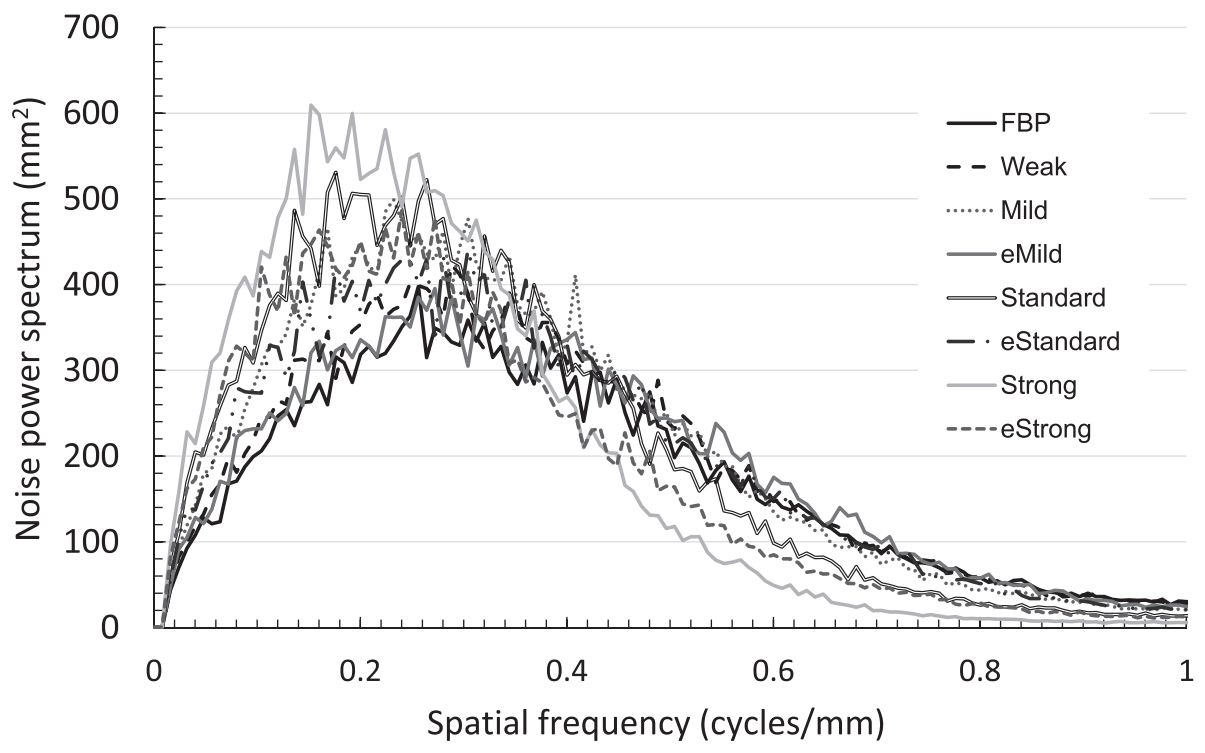

Fig. 6 NPS of the water phantom images (FBP and seven types of AIDR 3D).

1-2-2 で撮影した画像に直径 $10 \mathrm{~mm}, \mathrm{CT}$ 值差 30 HU の digital phantom にフィルタを付加して同心円 状に加算した Fig. 5)。使用したフィルタは $3 \times 3$ を用 い, none(フィルタなし), smoothing, Gaussianの 3 種類とした。 3 回撮影した画像を用いて, 1 個ずつ digital phantom を加算，毎回，同一部位にならないよ うに画像を回転し，アクリルの場所も変化させること で先入観を排除した。作成した 9 種類の画像を比較 し，10 名の放射線技師 (経験年数 2-20 年)によりアク リルと digital phantom が同等か否かの視認性を視覚 的に評価した。観察はすべて同一のモニ夕を用い，モ ニタから $50 \mathrm{~cm}$ の距離にて評価を行った。 ウィンド ウ幅は $200 \mathrm{HU}$ ， ウィンドウレベルは $50 \mathrm{HU}$ に固定し た。より同等と判定されたフィル夕を導き出すため次 式に示す合致率を使用した。
合致率 $(\%)=\frac{\text { 同等と判定した数 }}{30}$

(撮影回数 3 回 $\times 10$ 人)

ROC 解析は OR-DBM MRMC ver. 2.2 (Medical Image Perception Laboratory)を使用し分散分析によ る検定を行った。 2 群間の解析にはSPSS ver. 20 （IBM）を使用して Student t-testを用い， $\mathrm{p}<0.05$ にて 有意差ありとした，なお，本検討における観察結果の 公表に際しては当学会の倫理規定に従い観察者本人の 同意を得て行った。

\section{2. 結 果}

\section{2-1 NPS の比較}

8 種類 (FBP, Weak, Mild, eMild, Standard, eStandard, Strong, eStrong)の NPS を Fig. 6 に示す. Standard, Strong, eStrong の NPS は他の 5 種類と比較して低周 
Table 1 Sensitivity and specificity of FBP and seven types of AIDR 3D

\begin{tabular}{lclllllll}
\hline \hline & FBP & Weak & Mild & eMild & Std & eStd & Str & eStr \\
\hline Sensitivity & 0.94 & 0.95 & 0.86 & 0.79 & 0.62 & 0.77 & 0.43 & 0.47 \\
p-value & - & 0.740 & 0.785 & 0.253 & $<0.01$ & 0.043 & $<0.01$ & $<0.01$ \\
\hline Specificity & 0.79 & 0.80 & 0.68 & 0.83 & 0.84 & 0.79 & 0.76 & 0.76 \\
p-value & - & 0.240 & 0.076 & 0.255 & 0.161 & 0.989 & 0.620 & 0.625
\end{tabular}

Std: Standard, eStd: eStandard, Str: Strong, eStr: eStrong

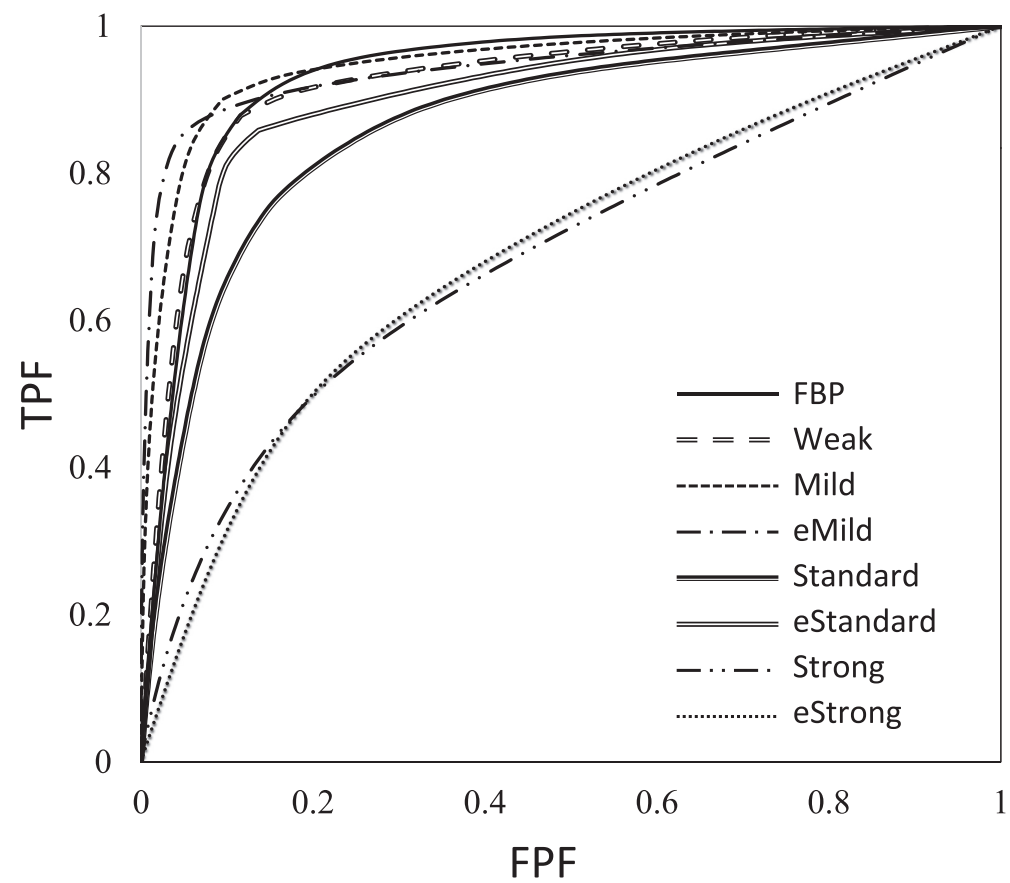

Fig. 7 ROC curves of FBP and seven types of AIDR 3D.

Table 2 AUC of FBP and seven types of AIDR 3D

\begin{tabular}{lcccccccc}
\hline \hline & FBP & Weak & Mild & eMild & Std & eStd & Str & eStr \\
\hline AUC & 0.952 & 0.931 & 0.938 & 0.950 & 0.881 & 0.911 & 0.718 & 0.732 \\
p-value & - & 0.127 & 0.796 & 0.959 & 0.020 & 0.092 & $<0.01$ & $<0.01$ \\
\hline
\end{tabular}

Std: Standard, eStd: eStandard, Str: Strong, eStr: eStrong

波成分が高く，高周波成分が低い解析結果を示した.

\section{2-2 FBP 画像と AIDR 3D 画像の感度と特異度}

FBP 画像およびAIDR 3D 画像の感度を Table 1 に 示す. Weak, Mild, eMild の感度は FBP 画像と比較 して有意差を認めなかった。 eStandardの感度は 0.77

と FBP 画像と比較して有意に低下し $(\mathrm{p}=0.043)$,

Standard, Strong, eStrong の感度も有意に低下した $(\mathrm{p}<0.01)$.

FBP 画像拈よびAIDR 3D 画像の特異度を Table 1
に示す。すべての AIDR 3D 画像はFBP 画像と比較 して有意差を認めなかった。

\section{2-3 FBP と AIDR 3D 画像の AUC}

FBP およびAIDR 3D 画像の ROC 曲線を Fig. 7

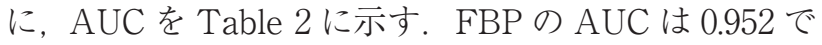
あった. Standardで若干の低下を示し, Strong, eStrong の AUC はそれぞれ $0.718,0.732$ と有意に低 下した $(\mathrm{p}<0.01)$. 


\section{2-4 Z 軸方向の評価}

1-5 で作成した画像にて設置した ROI 部分の CT 值 濃度曲線を Fig. 8〜10 に示す. $1 \mathrm{~mm}$ 厚, $2 \mathrm{~mm}$ 厚の $\mathrm{CT}$ 值は最大 CT 值にほとんど変動を認めなかった が, $3 \mathrm{~mm}$ 厚以上になると, 加算した digital phantom の含み方によって，CT 值が変動した. Digital phantom 中心が 50 枚目のときに $5 \mathrm{~mm}$ 厚の $\mathrm{CT}$ 值が最小 となり, 55 枚目のときは $4 \mathrm{~mm}$ 厚の C T 值が最小と なった。

\section{2-5 Digital phantom の視認性評価}

フィルタを付加した digital phantom 画像と模擬腫 瘤ファントム画像に㧍ける合致率を Table 3 に示す。 Gaussian フィルタを付加した digital phantom が最も アクリル球との合致率が高い結果となった。

\section{3. 考 察}

Digital phantom はコンピュータ上で任意の CT 值 を有する領域を作成した画像であるが，従来から報告 されている digital phantom 作成ツールは 1 枚の画像 に任意の大きさ $\mathrm{CT}$ 值をもった phantom を任意の座 標にプロットして作成するものであった ${ }^{16,18)}$ ，本研究 にて新たに開発した digital phantom 作成ツールは, 球状の phantom を作成することが可能である。つま り, $1 \mathrm{~mm}$ 以下の thin slice data を読み込み, 任意の phantom を作成, 画像の加算平均も可能であるため, 目的のスライス厚の画像を自由に書き出すことができ る.このツールを用いた低コントラスト検出能の評価 が可能か検証する必要があるため, われわれは水ファ ントムと自作模擬腫瘤ファントムを用いて新しい作成 ツールを用いた基礎データを作成し，低コントラスト 検出能の評価を行った。また, digital phantomはその まま使用すると加算した信号辺縁が矩形になるため幾 何学的となり不自然な印象を与える。したがって, digital phantom にフィルタを付加することで, 実際の 低コントラストモジュールと同等な表現が可能か検討 する必要があった。

検出感度は FBP と比較して Standard, Strong, eStrongは有意に低下した。同様にAUCにおいても Strong, eStrongの結果は有意に低下し，低コントラ スト検出能の低下を裏付ける結果となった，本研究に て使用した水 phantom 画像を用いた NPS の解析結果 においては, AIDR 3D の強度が強くなるほど低周波 成分の極端な上昇を認め, これが低コントラスト検出 能を低下させた要因であることを示し, 視覚評価結果 とも一致していると考える. 一方, Mild りり eMild,
Standard りり eStandard, Strongより eStrong の方 が確かに低周波ノイズは抑えられており, 特に Standard は eStandard に比べ AUC の低下が認めら れた。これはNPSの結果とも類似していた，本研究 では逐次近似応用再構成を使用した後の画像ノイズが SD 10 となるように設定したため, AIDR 3D 強度が強 いほど撮影線量は低くCTDIvol も少ない。ゅえに, 低線量ほど増加する低周波ノイズは AIDR 3D 強度を 強くしても抑制されないことから，異なるAIDR 3D 強度において同一画像 SD としても結果が異なること を証明している。本結果ではStandard, Strong, eStrongに抢いて病変検出能力の低下を認めたが, 実 臨床は画像の均一性が悪く複雑であるため, eStandard P Mild においても病変検出能力の低下を 認めることも十分考えられる.

また，本研究にて開発した作成ツールがパーシャル ボリューム効果を反映するか確認する必要があるた め, 書き出し時に digital phantom を含む割合が変わ るように加算中心をずらして CT 值差 $30 \mathrm{HU}$, 直径 5 $\mathrm{mm}$ の digital phantom を加算し, Z 軸方向の CT 值濃 度曲線を描くことでパーシャルボリューム効果の影響 についての評価を行った，その結果，加算したphantom 中心が 50 枚目のときは, $5 \mathrm{~mm}$ 厚では信号が二 分されるため, CT 值は著しく低下した。 このとき 4 $\mathrm{mm}$ 厚では加算した phantom 中心がスライス中心と なるため, $5 \mathrm{~mm}$ 厚よりも $10 \mathrm{HU}$ 程度 $\mathrm{CT}$ 值が高い結 果となった，一方，加算した phantom 中心が 55 枚目 のときは，前述した現象が逆転するため， $4 \mathrm{~mm}$ 厚の 方が $5 \mathrm{~mm}$ 厚の $\mathrm{CT}$ 值よりも低下した。これは書き 出す際のスライス位置損よびスライス枚数にて CT 值 が正確に加算平均された証拠である。したがって, 本 研究にて開発した作成ツールはパーシャルボリューム 効果を忠実に反映している。これは, 臨床画像を用い た評価でも同様の現象が起こるのは必然であるが, 実 臨床に扮いても腫瘤性病変は再構成するスライス位置 によって同様の現象が起きているため,このツールを用 いることで臨床においても同様の評価が可能となる.

フィルタを付加した digital phantom と実際にアク リル球を封入した自作模擬腫瘤ファントムを用いた視 認性評価では, Gaussian フィルタを付加した digital phantom が最もアクリル球と同等の視認性を得た.

この視認性はファントム周辺の「ボケ」が同等と判断 されたと考える. Digital phantom は周波数特性を反 映できない問題点を有するが, フィル夕を付加するこ とにより「ボケ」が表現されるため, この問題を解決 可能である. 本研究では臨床で実際に使用している条 


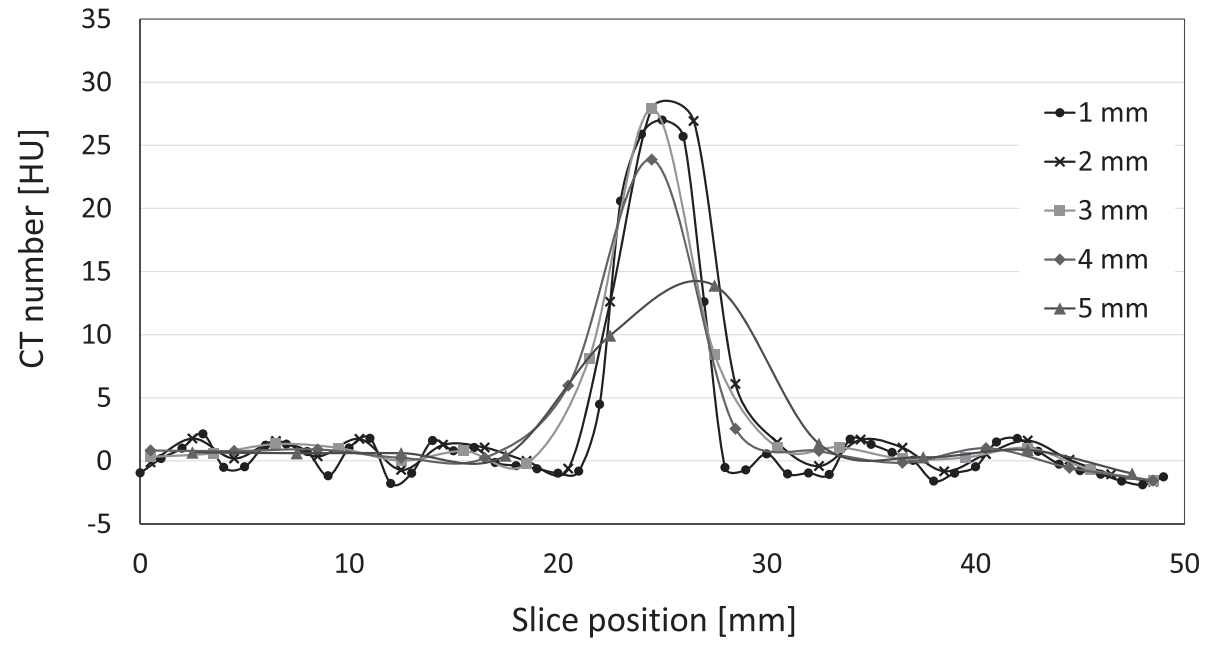

Fig. 8 CT value density curve of phantom CT number with different slice thickness (center slice number of added digital phantom=50).

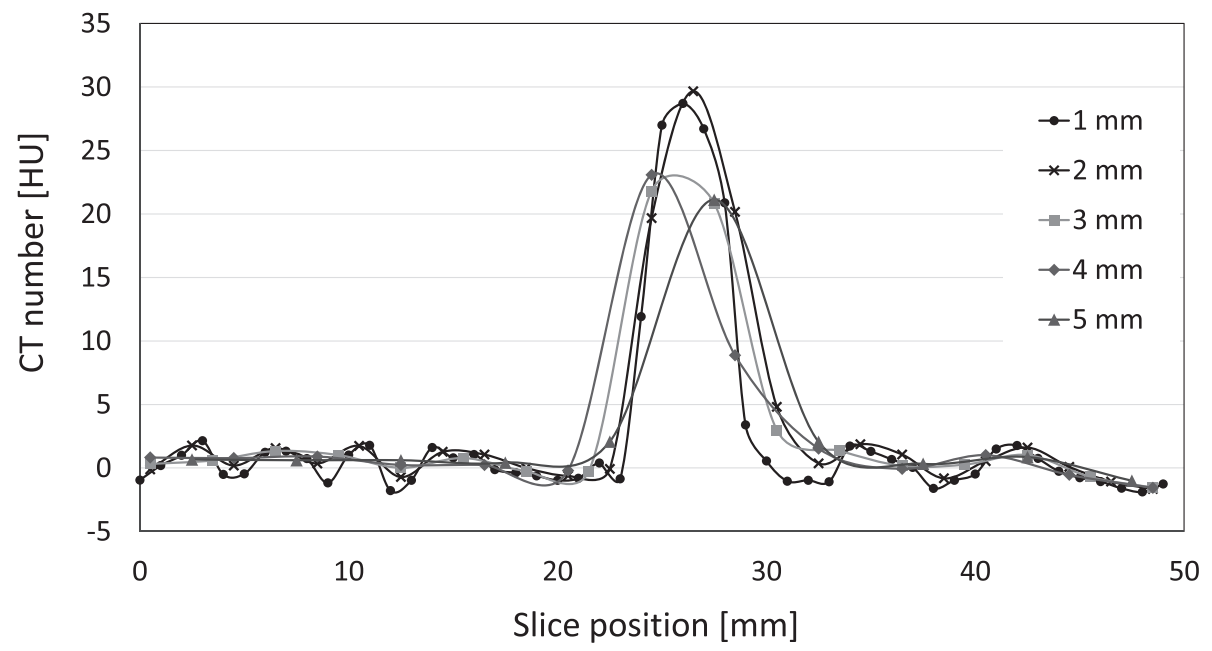

Fig. 9 CT value density curve of phantom CT number with different slice thickness (center slice number of added digital phantom=53).

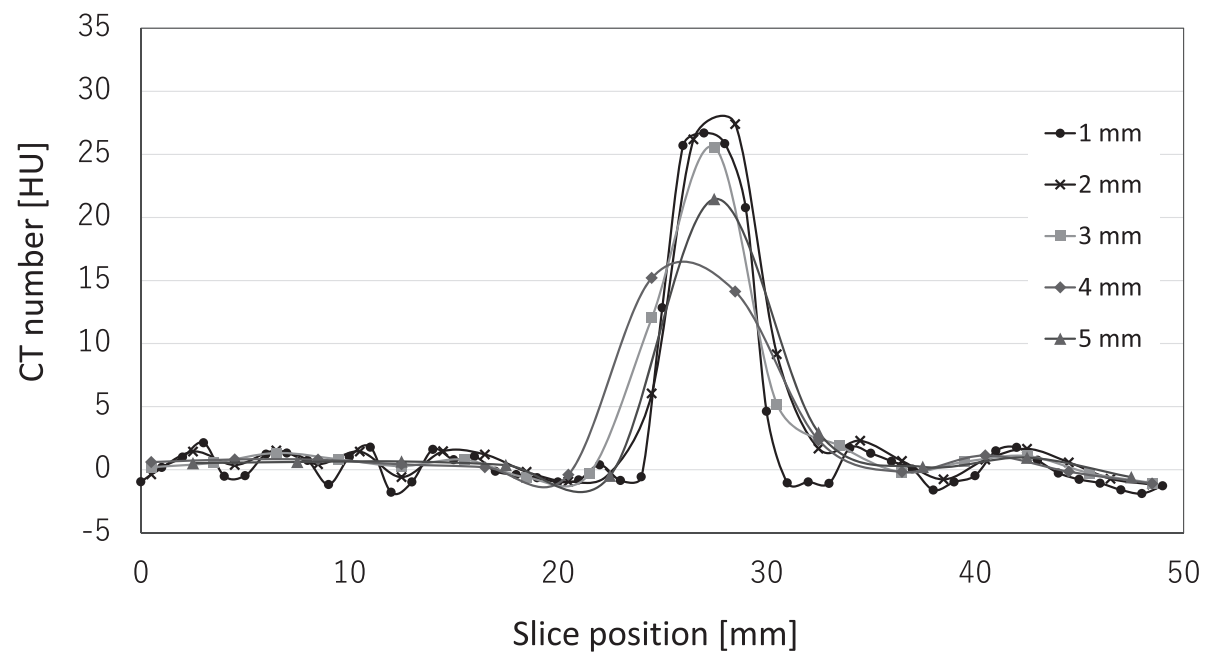

Fig. $10 \mathrm{CT}$ value density curve of phantom CT number with different slice thickness (center slice number of added digital phantom=55). 
Table 3 Match rate of additional filter image

\begin{tabular}{lccc}
\hline \hline & Equal & Not equal & Match rate (\%) \\
\hline None & 11 & 19 & 37 \\
Smoothing & 8 & 22 & 27 \\
Gaussian & 25 & 5 & 83 \\
\hline
\end{tabular}

件である再構成関数 FC 14, SD 10(Weak)の画像に対 して, Gaussian フィルタが最も適していると判断され た.フィルタを付加しない場合は digital phantom の 辺縁が矩形になるため, 幾何学的となり不自然な印象 を与え, smoothing フィルタは逆に辺縁が滑らかにな りすぎることで，ボケの要素が強くなったと考える。 しかし, 逐次近似応用再構成法は強度を強くするほど テクスチャが崩れるため, 同様に辺縁の視認性に影響 を与える. また, 使用している再構成関数も撮影部位 や装置, 施設によっても異なるため, 周波数特性を考 慮して digital phantom の大きさやフィルタ形状を決 定する必要がある。

肝臓における悪性腫瘍検索目的の dynamic study は

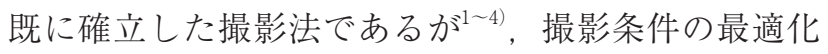
の根拠を示した報告はない. しかし肝臟は病変部と肝 実質のわずかなコントラスト差を描出可能な画質が必 要であり, コントラストはノイズの影響を受ける ${ }^{19,20)}$. 更に最近の CT 装置の進歩によって逐次近似応用再構 成法 ${ }^{10 \sim 13)}$, 逐次近似再構成法 ${ }^{21)}$ が導入され，ますます 低コントラスト検出能の評価が複雑化している。ほと んどの装置に標準装備されている AEC は，管電流を 制御することで各スライスにおける画質を均一化する ことが可能であるが, AEC の目標值は SD であること が多く, 同一SD でも AIDR 3D の強度によって画質 は変化する. Berta らは, iterative reconstructionの 評価に signal to noise ratio (SNR)を用い, NPS のピー クが低周波側にシフトすることにより低周波ノイズが 強調され SNR の低下を招くことを報告しており ${ }^{22)}$, Urikura らは NPS を加味した新しい low-contrast object specific contrast-to-noise ratio $\left(\mathrm{CNR}_{\mathrm{LO}}\right)$ を用い, 従 来の CNR では同等の画質でも AIDR 3D の強度が強 いほど $\mathrm{CNR}_{\mathrm{LO}}$ が低下することで，低コントラスト検 出能にNPS が関与していることを証明した ${ }^{23)}$. 本研 究におけるわれわれの評価結果もこれらの報告に酷似 している。したがって, digital phantom は単に再構成 後の画像に任意の模擬腫瘤として信号を加算するッー ルであるが16), AIDR 3D を加味した場合の視覚評価も 可能であることを証明した。これを臨床画像に応用す ることにより, 腫瘤性病変の大きさや濃度差の描出限
界に合わせた撮影画質を求めることができるため, 肝 臟領域における撮影条件の適正化が策定可能になると 考える，肝臓に㧈いて $10 \mathrm{~mm}$ 以上の悪性腫瘍を認め た場合は治療対象となるため ${ }^{24)}$, 少なくとも $10 \mathrm{~mm}$ の腫瘤性病変は確実に検出できなければならない。し たがって, 大きさの基準は既に存在するため, 濃度差 の要素を加味することで適正化の策定は現実化すると 考える，われわれは，臨床画像を用いた digital phantom の検出能評価において濃度差 1\%の模擬腫瘤は検 出能が極端に悪くなることを示し ${ }^{16)}$ ，この結果は腫瘍一 肝実質の濃度差が $15 \mathrm{HU}$ 以上しか検出していない藤 谷らの報告9)に矛盾しない，更に本研究のわれわれの 結果を融合することによって，Z 軸にも対応した新し い digital phantom と臨床画像における病変検出能の 評価が可能となるだろう。無論, このツールは肝臓の みならず，他の撮影部位においても利用可能である.

本研究の結果では, FBP とWeak, Mild, eMild, Standard, eStandardの間に有意差はみられなかっ た．本研究は水ファントムを用いた均一な画像に対し ての評価であるため, 信号の検出は容易であると考え るが，実臨床では条件が悪くなることが予想される．

肝㵴を例にとると，まず肝実質は均一ではない，動脈 後期相では肝動脈は造影されているため高吸収であ り，門脈は脾静脈の流入を受けている時間带のため濃 染され始めている。 これに対し肝静脈は低吸収である ためさまざまな濃度が混在しているのである，その中 で CT 值差 $15 \mathrm{HU}$ 程度の信号 ${ }^{9)}$ をつけるのは容易 ではない. したがって, 本研究では有意差が出なかっ たAIDR 3D 強度においても低コントラスト検出能が 劣化することは十分考えられる。

本研究に扔けるリミテーションもいくつか挙げられ る.はじめに, digital phantom は基本的に pixel size で大きさが決定するため, 比較する画像の FOV size が異なると, 同一 pixel size でも大きさが変化する. 特に, 模擬腫瘤の辺縁形状が臨床画像と同等となる必 要があり, 本研究では不可フィル夕を用いることに よって模擬腫瘤の視認性を近似した。しかし, 使用し たフィルタは $3 \times 3$ のみであり, 忠実に腫瘤を再現して いるかは定かとはいえない.したがって，極端に大き い，または小さい FOV size を用いる場合は使用する 付加フィルタの形状や pixel size を考慮する必要があ る. 同様に，極端に大きい，または小さい模擬腫瘤を 作成する場合もフィルタの形状や pixel size を考慮す る必要がある。更に, phantomが球状であるため, 原 発性肺がんのような不整形な腫瘤を再現できない，今 後, $5 \times 5$ や $7 \times 7$ の付加フィルタへの対応や, 球体以外 
の模擬腫瘤作成が可能か検討する必要がある。

しかし, 新しい digital phantom 作成ツールは逐次 近似応用再構成の画像に対しても低コントラスト検出 能評価が可能であり，臨床画像に応用することによっ て, 腫瘤性病変の大きさ, 濃度の検出限界を示すこと が可能となることで肝臟領域の撮影条件標準化に寄与 するかもしれない.

\section{4. 結 語}

Z 軸方向にも対応した新しい digital phantom 作成 ッールはさまざまな大きさ, CT 值差の digital phantom が作成できるため, 低コントラスト検出能評価に
利用可能であり, 肝臟領域の撮影基準を策定するため の画質評価にも応用できる。

\section{謝 辞}

本研究に協力していただいた，担当諸兄に媣く感謝 いたします。

また, 本研究は, 北海道支部の平成 29 年度放射線技 術研究の助成を受けて行われました。ここに深く感謝 申し上げます。

なお，本論文の論旨は第 72 回日本放射線技術学会 総会学術大会 (2016 年, 横浜)にて発表した。

\section{参考文献}

1) Sultana S, Awai $K$, Nakayama $Y$, et al. Hypervascular hepatocellular carcinomas: bolus tracking with a 40-detector CT scanner to time arterial phase imaging. Radiology 2007; 243 (1): 140-147.

2) 岡田真広, 香川祐毅, 村上卓道, 他. マルチスライス CT による肝画像診断の進歩 高速化・高分解能化の動向. 肝胆膵画像 2011; 13(1): 37-44.

3) Yanaga $Y$, Awai K, Nakaura $T$, et al. Optimal contrast dose for depiction of hypervascular hepatocellular carcinoma at dynamic CT using 64-MDCT. AJR Am J Roentgenol 2008; 190 (4): 1003-1009.

4) Koiwahara G, Tsuda T, Matsuda M, et al. Different enhancement of the hepatic parenchyma in dynamic CT for patients with normal liver and chronic liver diseases and with the dose of contrast medium based on body surface area. Jpn J Radiol 2015; 33(4): 194-200.

5) Goodenough DJ, Weaver KE. Factors related to low contrast resolution in CT scanners. Comput Radiol 1984; 8(5): 297-308.

6) Wang G, Vannier MW. Low-contrast resolution in volumetric $\mathrm{x}$-ray CT-analytical comparison between conventional and spiral CT. Med Phys 1997; 24(3): 373-376.

7) Verdun FR, Denys A, Valley JF, et al. Detection of lowcontrast objects: experimental comparison of single- and multidetector row CT with a phantom. Radiology 2002; 223(2): 426431.

8) Shin HO, Falck CV, Galanski M. Low-contrast detectability in volume rendering: a phantom study on multidetector-row spiral CT data. Eur Radiol 2004; 14(2): 341-349.

9）藤谷哲也, 熊野正士, 村上卓道. ダイナミックマルチスラ イス CT に打ける多血性肝細胞癌検出に最適な造影剂量 の検討。近畿大医誌 2012;37(3,4): 155-162.

10) Matsuki $M$, Murakami $T$, Juri $H$, et al. Impact of adaptive iterative dose reduction (AIDR) 3D on low-dose abdominal CT: comparison with routine-dose CT using filtered back projection. Acta Radiol 2013; 54(8): 869-875.

11) Seki S, Koyama $H$, Ohno $Y$, et al. Adaptive iterative dose reduction 3D (AIDR 3D) vs. filtered back projection: radiation dose reduction capabilities of wide volume and helical scanning techniques on area-detector $\mathrm{CT}$ in a chest phantom study. Acta Radiol 2016; 57(6): 684-690.
12）木原 聡, 村崎裕生, 船間芳憲, 他. マルチディテク夕 CTにおける 逐次近似画像再構成法を用いた線量低減お よび画質改善. 日放技学誌 2011; 67(11): 1426-1432.

13）高田忠徳, 市川勝弘, 林 弘之, 他. 逐次近似再構成法を 応用した新しい画像再構成法に対する画質評価. 日放技 学誌 2012; 68(4): 404-412.

14）大村知已, 豊嶋英仁, 佐藤祐一郎, 他. 逐次近似応用再構 成法を用いた頭部 CT-Perfusionの撮影線量低減の検討。 日放技学誌 2013; 69(11): 1218-1224.

15）多田佳司，内田幸司，金山秀和，他. 急性期脳梗塞 CT 検 查に打ける逐次近似応用再構成法の有用性. 日放技学誌 2015; 71(11): 1090-1095.

16）原田耕平, 宮下宗治, 平野雄士, 他. デジタルファントム と臨床画像を用いた肝藏領域における低コントラスト分 解能の評価. 日放技学誌 2010; 66(12): 1561-1568.

17) Digital phantom creation tool. http://www.sapmed.ac.jp/ $\sim$ katagiri/index.php/Digital-Phantom-Builder (Accessed 2018/ $4 / 30)$.

18) Kudo K, Christensen S, Sasaki M, et al. Accuracy and reliability assessment of $\mathrm{CT}$ and MR perfusion analysis software using a digital phantom. Radiology 2013; 267(1): 201-211.

19) Abdelmoumene A, Chevallier P, Chalaron $M$, et al. Detection of liver metastases under $2 \mathrm{~cm}$ : comparison of different acquisition protocols in four row multidetector-CT (MDCT). Eur Radiol 2005; 15(9): 1881-1887.

20) Kanal KM, Chung JH, Wang J, et al. Impact of incremental increase in CT image noise on detection of low-contrast hypodense liver lesions. Acad Radiol 2014; 21(10): 1233-1239.

21) Pickhardt PJ, Lubner MG, Kim DH, et al. Abdominal CT with model-based iterative reconstruction (MBIR): initial results of a prospective trial comparing ultralow-dose with standard-dose imaging. AJR Am J Roentgenol 2012; 199(6): 1266-1274.

22) Berta L, Mascaro L, Feroldi P, et al. Optimisation of an MDCT abdominal protocol: Image quality assessment of standard vs. iterative reconstructions. Phys Med 2014; 30(3): 271-279.

23) Urikura A, Hara T, Ichikawa $K$, et al. Objective assessment of low-contrast computed tomography images with iterative reconstruction. Phys Med 2016; 32(8): 992-998.

24）日本肝臓学会編. 科学的根拠に基づく肝癌診療ガイドラ イン 2013 年版. 東京: 金原出版, 2013. 